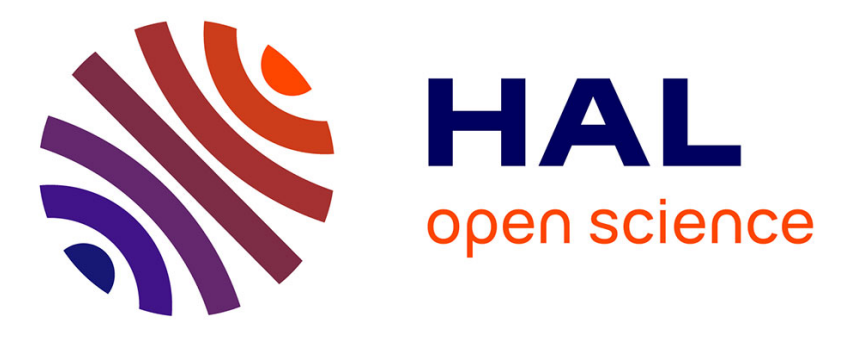

\title{
Investigation of LaVO3 based compounds as a photovoltaic absorber
}

\author{
M. Jellite, J.-L. Rehspringer, M. Fazio, D. Muller, G. Schmerber, G. \\ Ferblantier, S. Colis, A. Dinia, M. Sugiyama, A. Slaoui, et al.
}

\section{- To cite this version:}

M. Jellite, J.-L. Rehspringer, M. Fazio, D. Muller, G. Schmerber, et al.. Investigation of LaVO3 based compounds as a photovoltaic absorber. Solar Energy, 2018, 162, pp.1-7. 10.1016/j.solener.2017.12.061 . hal-02136394

\section{HAL Id: hal-02136394 \\ https://hal.science/hal-02136394}

Submitted on 13 Dec 2021

HAL is a multi-disciplinary open access archive for the deposit and dissemination of scientific research documents, whether they are published or not. The documents may come from teaching and research institutions in France or abroad, or from public or private research centers.
L'archive ouverte pluridisciplinaire HAL, est destinée au dépôt et à la diffusion de documents scientifiques de niveau recherche, publiés ou non, émanant des établissements d'enseignement et de recherche français ou étrangers, des laboratoires publics ou privés. 


\section{Investigation of $\mathrm{LaVO}_{3}$ Based Compounds as a Photovoltaic Absorber}

M. Jellite ${ }^{1}$, J.-L. Rehspringer ${ }^{2}$, M. A. Fazio ${ }^{3}$, D. Muller ${ }^{1}$, G. Schmerber ${ }^{2}$, G. Ferblantier ${ }^{1}$, S. Colis $^{2}$, A. Dinia ${ }^{2}$, M. Sugiyama ${ }^{4}$, A. Slaoui ${ }^{1}$, D. Cavalcoli ${ }^{3}$, T. Fix ${ }^{1 *}$

${ }^{1}$ ICube laboratory (Université de Strasbourg and CNRS), 23 rue du Loess BP 20 CR, 67037 Strasbourg Cedex 2, France

${ }^{2}$ Institut de Physique et Chimie des Matériaux de Strasbourg (IPCMS), UMR 7504 CNRS, University of Strasbourg (UDS), 23 rue du Loess, F-67034 Strasbourg Cedex 2, France

${ }^{3}$ Dipartimento di Fisica e Astronomia, Università di Bologna, Viale Berti Pichat 6/2, 40127 Bologna, Italy

${ }^{4}$ Faculty of Science and Technology / Research Institute for Science and Technology, Tokyo University of Science, Noda, Chiba 278-8510, Japan

* Corresponding author. Tel.: +33 388106334, Fax +33 388106548. E-mail address: tfix@unistra.fr 
Abstract:

Bulk $\mathrm{LaVO}_{3}(\mathrm{LVO})$ is known to provide an optical bandgap of $1.1 \mathrm{eV}$ which is interesting for photovoltaic applications. Here, we compare the properties of LVO thin films using different techniques, namely pulsed laser deposition, spin coating by solgel and sputtering. ZnO/LVO $p-n$ junctions were fabricated in order to obtain solar cell architectures. The grown films were analyzed with Surface photovoltage and Scanning Kelvin Probe Microscopy. The analysis of the junctions showed that the photogenerated electron-hole pairs are poorly separated and therefore not efficiently collected. LVO has shown the particularity to provide very high work function $(4.6 \mathrm{eV})$ and a great dependence of the electrical and optical properties on the growth conditions, including the oxygen stoichiometry and the La/V ratio of the films.

Keywords: oxides; thin film solar cells; solgel; optical materials 


\section{Introduction}

Inorganic thin film photovoltaics (PV) are mainly based on CdTe, amorphous Si or CIGS. In the most recent times, hybrid organo-metal halide perovskites have emerged with reported solar cell conversion efficiencies above $21 \%$. However, these materials can present stability, reliability and toxicity issues but research has considerably progressed recently on these challenges. Alternative inorganic oxides could offer significant advantages regarding these issues while aiming at high conversion efficiencies. The ideal bandgap for a single bandgap active photovoltaic layer is around $1.3 \mathrm{eV}$ for the solar spectrum on Earth. However oxides with such a low bandgap are scarce. To date, one of the most studied oxide as an active PV layer is cuprous oxide, $\mathrm{Cu}_{2} \mathrm{O}$. Its bandgap is around $2.1 \mathrm{eV}$ which is not ideal for the solar spectrum. The conversion efficiencies are generally found to be around 4 \% (levskaya et al., 2015). Table 1 shows the most common oxide absorbers used to date in functional solar cells (SC). An emerging type of oxide SC is called ferroelectric photovoltaics (FE-PV), with recently improved conversion efficiencies of $3.98 \%$ for $\mathrm{BiFeO}_{3}$ (Tiwari et al., 2015) and $8.1 \%$ with $\mathrm{Bi}_{2} \mathrm{FeCrO}_{6}$ (Nechache et al., 2015).

Oxide based SC, either based on $p$ - $n$ junctions or ferroelectricity, require the development of low bandgap oxides. One category of such oxides can be found among Mott insulators (MI). $\mathrm{MI}$ are materials that behave as insulators while they are predicted to be conductors under conventional band theories. However, MI can easily become conductive due for example to strain, defects, and oxygen stoichiometry. This phenomenon is called the Mott transition. Examples of $\mathrm{Ml}$ are $\mathrm{NiO}, \mathrm{LaVO}_{3}, \mathrm{YTiO}_{3}, \mathrm{YVO}_{3}, \mathrm{La}_{2} \mathrm{CuO}_{4}, \mathrm{Sm}_{2} \mathrm{CuO}_{4}, \mathrm{LaMnO}_{3}$ and $\mathrm{SrMnO}_{3}$ (Nakamura et al., 2010; Arima et al., 1993).

In this work, we focus on the growth of $\mathrm{LaVO}_{3}$ (LVO) thin films by different techniques and we investigate their optical and electrical properties for possible photovoltaic applications. The state of the art of MI based SC with an emphasis on LVO will be first presented. Then, we will show different fabrication routines for LVO thin film fabrication, giving rise to highly tunable properties such as conductivity and optical bandgap. Finally, we will describe the integration of LVO into SC and the limiting factors hindering the achievement of high efficiencies. 


\begin{tabular}{|c|c|c|c|}
\hline Oxide absorber & $\begin{array}{l}\text { Bandgap } \\
\text { (eV) }\end{array}$ & $\begin{array}{l}\text { Efficiency } \\
\text { (\%) }\end{array}$ & Reference \\
\hline $\mathrm{BiMnO}_{3}$ & 1.2 & 0.1 & Chakrabartty et al., 2013 \\
\hline $\mathrm{CuO}$ & 1.2 & 0.08 & Dimopoulos et al., 2013 \\
\hline $\mathrm{Bi}_{2} \mathrm{FeCrO}_{6}$ & $1.4-2.1$ & 8.1 & Nechache et al., 2015 \\
\hline $\mathrm{CO}_{3} \mathrm{O}_{4}$ & 1.5 & 0.02 & Kupfer et al., 2015 \\
\hline h-LuMnO $3 / \mathrm{h}-\mathrm{YMnO}_{3}$ & $1.5-1.55$ & 0.11 & Han et al., 2015 \\
\hline $\mathrm{Cu}_{2} \mathrm{O}$ & 2.1 & 8.1 & Minami et al., 2016 \\
\hline $\mathrm{BiFeO}_{3}$ & 2.2 & 3.98 & Tiwari et al., 2015 \\
\hline$\left(\mathrm{Pb}_{0.97} \mathrm{La}_{0.03}\right)\left(\mathrm{Zr}_{0.52} \mathrm{Ti}_{0.48}\right) \mathrm{O}_{3}$ & 3.3 & 0.28 & Qin et al., 2008 \\
\hline $\mathrm{Pb}\left(\mathrm{Zr}_{0.53}, \mathrm{Ti}_{0.47}\right) \mathrm{O}_{3}$ & 3.4 & 0.22 & Chen et al., 2012 \\
\hline $\mathrm{NiO}$ & 3.7 & 0.02 & Warasawa et al., $2013^{*}$ \\
\hline
\end{tabular}

Table 1: examples of oxide absorber based SC, with their bandgap and solar cell efficiency. * intentionally transparent to visible light SC.

\section{State of the art}

Not all Ml exhibit suitable bandgaps and properties for photovoltaics. The evolution of the optical gap has been studied in Arima et al., 1993. for $\mathrm{LaMeO}_{3}$ and $\mathrm{YMeO}_{3}$ compounds where $\mathrm{Me}$ is a trivalent $3 \mathrm{~d}$ transition metal. Among the different materials, $\mathrm{YTiO}_{3}, \mathrm{YVO}_{3}, \mathrm{LaVO}_{3}$, and $\mathrm{LaMnO}_{3}$ present optical gaps close to $1.1 \mathrm{eV}$ and can thus present an interest for PV applications.

MI - based SC are discussed theoretically in Manousakis, 2010. For narrow-gap MI, it is claimed that high quantum efficiencies of such SC can be obtained thanks to impact ionization and generation of multiple electron-hole pairs. Another theoretical study on MI SC but based on p-n junction mechanisms can be found in Charlebois et al., 2013.

There have been attempts to obtain MI based SC experimentally. For example, MI based heterojunctions (including $\mathrm{La}_{2} \mathrm{CuO}_{4}, \mathrm{Sm}_{2} \mathrm{CuO}_{4}, \mathrm{LaMnO}_{3}$ and $\mathrm{SrMnO}_{3}$ ) were studied by Nakamura et al. (2010). Very low photocurrents were obtained due to short minority-carrier diffusion lengths as compared to traditional semiconductors. The reason proposed for this is 
the strong electron correlation that enhances the effective carrier mass and lowers the electron mobility (Nakamura et al., 2010, 2007; Choi et al., 2010).

LVO is a p-type semiconductor in the bulk (Webb et al., 1976; Madelung et al., 2000). Previous studies showed that LVO is orthorhombic at room temperature, with lattice parameters of $a=0.5555 \mathrm{~nm}, b=0.5553 \mathrm{~nm}$, and c=0.7848 nm (Bordet et al., 1993). LVO films were grown by pulsed laser deposition (PLD) on different single crystal substrates (Masuno et al., 2004) and the oxygen partial pressure during growth was varied (Hotta et al., 2006a). It was shown in Hotta et al., 2007b and He et al., 2012 that electronic reconstructions can occur at the $\mathrm{LaVO}_{3} / \mathrm{SrTiO}_{3}$ interface leading to conductive interfaces, similarly to the wellknown $\mathrm{LaAlO}_{3} / \mathrm{SrTiO}_{3}$ case (Fix et al., 2009). However, the diffusion of oxygen vacancies in the $\mathrm{SrTiO}_{3}$ substrate plays a role in the metallicity of the interface (Rotella et al., 2015). Following this idea of electronic reconstructions at the $\mathrm{LaVO}_{3} / \mathrm{SrTiO}_{3}$ interface, $\mathrm{SrTiO}_{3}(001)$ $/ /\left(\mathrm{LaVO}_{3} / \mathrm{LaFeO}_{3}\right)_{\mathrm{n}}$ heterostructures were proposed theoretically as $\mathrm{SC}$, in which an internal potential gradient favours the separation of photogenerated electron-hole pairs (Assmann et al., 2013). In addition, experimental work on the fabrication of PLD grown LVO based solar cells is presented in Wang et al., 2015. Among the various LVO SC structures fabricated, only DSSC-type SC provided PV properties, however with low conversion efficiency (0.12 \%). This was attributed to trap-assisted recombinations and low minority carrier diffusion length (Wang et al., 2015), which is consistent with the interpretation of Nakamura et al. for similar MI materials (Nakamura et al., 2010, 2007).

To overcome these limitations, one possibility is to tune the carrier concentration of such materials. There are several possibilities to do this such as varying the La/V ratios and oxygen stoichiometry, and introducing additional substituents for La or V. Indeed, it was shown that $V$ is present in 3+ and 4+ valence (Gharetape et al., 2011).

In the following, we will present our experimental procedure for growing LVO thin films as well as their structural, optical and electrical properties.

\section{Experimental}

Three LVO thin film fabrication techniques were used, namely pulsed laser deposition (PLD), spin coating by solgel and magnetron sputtering. 
PLD was performed using a KrF laser with $10 \mathrm{~Hz}$ repetition rate and a fluence of around 2 $\mathrm{J} / \mathrm{cm}^{2}$ on the target. The target used was made of $\mathrm{LaVO}_{4}$ prepared by solid state synthesis starting from $\mathrm{La}_{2} \mathrm{O}_{3}$ and $\mathrm{V}_{2} \mathrm{O}_{5}$ powders, milled, pressed and sintered at $700{ }^{\circ} \mathrm{C}$ for $10 \mathrm{~h}$ in air. The substrates used were $\mathrm{SrTiO}_{3}(001)$ and 1 at. \% Nb: $\mathrm{SrTiO}_{3}$ (001) at a deposition temperature of $600{ }^{\circ} \mathrm{C}$. The films were deposited and cooled down in either vacuum or in a $2.5 \cdot 10^{-5} \mathrm{mbar}_{2}$ atmosphere.

Solution processed films were obtained as follows. First the required quantities of lanthanum (III) nitrate hexahydrate, vanadium (III) acetylacetonate, and barium nitrate (for Ba doping) were added into deionized water. Citric acid was dissolved in the solution together with ethylene glycol. A strong dark colored solution was obtained, excess of water was evaporated and a viscous liquid without precipitate appeared. This liquid was then spin coated on quartz substrates. The samples were heated at $400^{\circ} \mathrm{C}$ with $1 \mathrm{~h}$ dwell in air, leading to the formation of a $\mathrm{LaVO}_{4}$ film. Finally, post annealing was performed under $\mathrm{H}_{2}$ at $900{ }^{\circ} \mathrm{C}$ with $1 \mathrm{~h}$ dwell to form the required $\mathrm{LaVO}_{3}$ phase.

$\mathrm{RF}$ (Radio-Frequency) magnetron reactive sputtering of $\mathrm{LaVO}_{3}$ was performed with an Orion 3 device from AJA International. Co-sputtered targets of La and V (Neyco) were used, with a power of $50 \mathrm{~W}$ and 100-130 $\mathrm{W}$ respectively. The substrates used were n-type (P) Fz Si (100) $(0.8-2.5 \Omega \cdot \mathrm{cm})$ and quartz substrates, heated at $400{ }^{\circ} \mathrm{C}$. The Si substrates were cleaned before deposition using the "piranha" procedure and final HF dipping to remove the oxide at the surface. The $\mathrm{Ar} / \mathrm{O}_{2}$ gas flows were set to $8 / 2 \mathrm{sccm}$, with a deposition pressure of 3.4 mTorr. The substrate to target distance was kept constant at about $120 \mathrm{~mm}$. Film thicknesses were in the 100-500 nm range. Post-deposition annealing was performed under $\mathrm{H}_{2}$ at $900{ }^{\circ} \mathrm{C}$ with $1 \mathrm{~h}$ dwell to form the required $\mathrm{LaVO}_{3}$ phase. For the formation of $\mathrm{p}-\mathrm{n}$ junctions, ZnO was deposited as described in Soumahoro et al., 2011.

For PLD samples, $x$-ray diffraction (XRD) was performed in $\theta-2 \theta$ configuration with a Rigaku SmartLab x-ray diffractometer with a CuK $\alpha 1$ beam of $\lambda=0.154056 \mathrm{~nm}$. The same equipment was used for $\mathrm{x}$-ray reflectometry (XRR) to determine the film thickness. For the sol-gel and sputtered samples, a Bruker D8 diffractometer with $\mathrm{CuK}_{\alpha 1}$ beam was used.

The distribution and concentration of the chemical elements ( $\mathrm{La}, \mathrm{V}$, and $\mathrm{O}$ ) along the growth direction was obtained by Rutherford backscattering spectroscopy (RBS).

The optical properties were measured with a UV-Vis-IR Perkin-Elmer Lambda 19 spectrophotometer, and an HORIBA Uvisel Lt M200 FGMS (210-880 nm) spectroscopic 
ellipsometer. The ellipsometric dispersion model used for $\mathrm{LaVO}_{3}$ is based on the TaucLorentz formula (Jellison et al, 1996). Hall effect was measured at room temperature to investigate the electrical properties of the thin films, using an Ecopia Hall effect system. I-V characteristics were performed at room temperature using an Oriel Solar Simulator in AM1.5G conditions and a Keithley 2450 SourceMeter.

Surface photovoltage (SPV) spectroscopy was performed using a short arc Xe lamp as a white light source, a SPEX 500M spectrometer, a chopper (300CD model by Scitec Instruments) as a reference frequency for the lock-in amplifier, used to evaluate the low SPV signal. A metal-insulator-semiconductor structure was used to extract the surface photovoltage signal. The set-up was realised by using an ITO (Indium Tin Oxide) coated glass slide as the transparent electrode and placing it in front of the sample to achieve the plate capacitor configuration, where the insulating spacer is simply air. Further details on the system can be found in Cavalcoli et al., 2015.

Atomic Force Microscopy (AFM) and Scanning Kelvin Probe Microscopy (SKPM) measurements were performed with a Park NX10 atomic force microscope at room temperature and ambient atmosphere. Au coated tips with a nominal curvature radius below $50 \mathrm{~nm}$ were employed for morphological and electrical maps, respectively.

Force Range technique has been used for SKPM electrical characterization. It relies on the fact that the two forces between the tip and the sample, i.e. Van der Waals and electrostatic forces, have different dominant regimes. Van der Waals forces are proportional to $r^{-6}$, while electrostatic forces are proportional to $r^{-2}$, where $r$ is the tip-sample distance. Thus, Van der Waals forces are dominant when the tip is close to the sample, while they rapidly decrease as the tip moves away, when electrostatic forces become dominant. In this technique, the first scan is performed near the sample, in the region where Van der Waals forces are dominant. Then, the tip-sample distance is increased to place the tip where electrostatic forces are dominant and the Electrical Force Microscopy (EFM) image is acquired (ParkAFM, 2017). Applying an AC potential to the conductive tip, the surface potential of the sample can be extracted from SKPM measurements.

\section{Pulsed laser deposition films}


The LVO films were grown by PLD using $\mathrm{SrTiO}_{3}$ (001) substrates (STO). Two deposition conditions were used, either growth in vacuum or growth in $2.5 \cdot 10^{-5} \mathrm{mbar}_{2}$ with cooling down in the same conditions. Both methods led to phase pure LVO as observed by XRD (Figure 1). The LVO reflections of the vacuum grown samples are shifted towards low angles, which indicates an expansion of the LVO lattice in the out-of-plane direction due to the deficiency in oxygen. We found pseudo-cubic out-of-plane lattice parameters of $0.3955 \mathrm{~nm}$ and $0.4012 \mathrm{~nm}$ in oxygen and vacuum respectively, close to the values observed in Masuno et al., 2004.

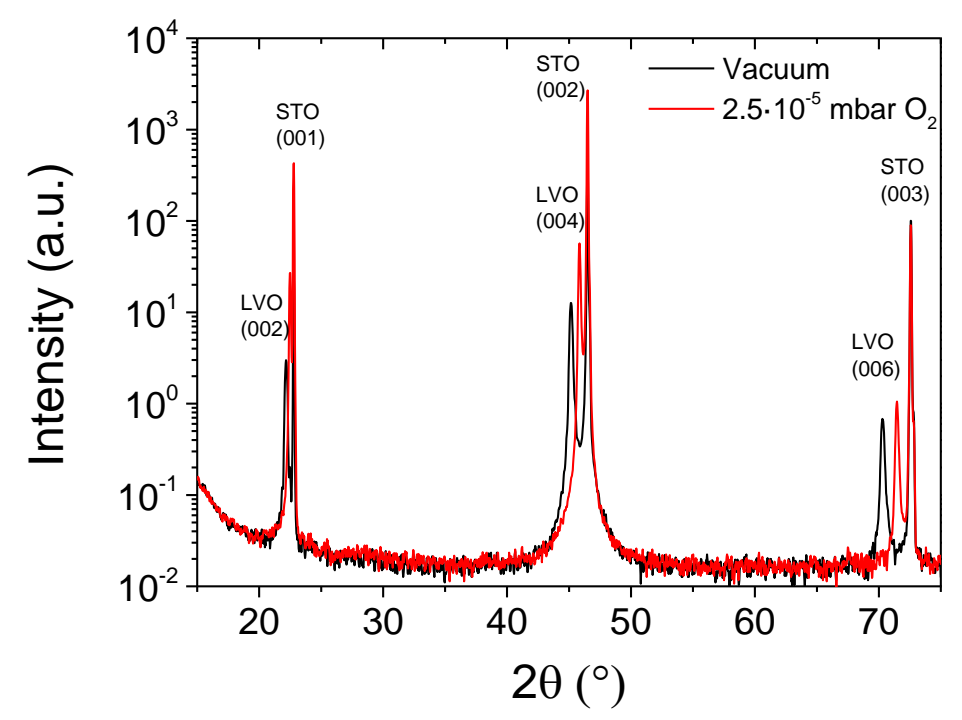

Figure 1: Room temperature $\theta-2 \theta$ XRD spectra showing STO (001)//LVO samples obtained by PLD either in vacuum or in a low oxygen atmosphere.

The overall properties of the films grown by PLD are presented in Table 2. The sample grown in vacuum provides a nearly ideal composition, while the sample grown in oxygen is deficient in La. The optical bandgap was determined by spectroscopic ellipsometry and ranges from $1.0 \mathrm{eV}$ for the vacuum sample to $1.9 \mathrm{eV}$ for the sample made under oxygen atmosphere (Figure 2). The value of $1.0 \mathrm{eV}$ is matching the reported value of the bulk (Madelung et al., 2000). Both type of samples were n-type with a carrier concentration in the $10^{19}-10^{20} \mathrm{~cm}^{-3}$ range. It can be noted that the sample grown in vacuum has an absorption coefficient one order of magnitude higher than c-Si in the 1.1-2.5 eV range. 
LVO was also grown by PLD on Nb-STO substrates which are n-type conductors. As expected for a n-type LVO on n-type Nb-STO, no photocurrent could be observed.

\begin{tabular}{|l|l|l|}
\hline & \multicolumn{2}{|c|}{ Atmosphere } \\
\hline & Vacuum & $2.5 \cdot 10^{-5} \mathrm{mbar}_{2}$ \\
\hline Deposition rate $(\AA ̊$ /pulse) & 0.02 & 0.02 \\
\hline Composition & $\mathrm{La}_{1} \mathrm{~V}_{1} \mathrm{O}_{3}$ & $\mathrm{La}_{1} \mathrm{~V}_{1.1} \mathrm{O}_{3.3}$ \\
\hline Bandgap (eV) density & 1.0 (indirect) & 1.9 (indirect) \\
\hline $\begin{array}{l}\text { Carrier } \\
\left(\mathrm{cm}^{-3}\right)\end{array}$ & $\mathrm{n} .8 \cdot 10^{20}$ & $\mathrm{n} 1.2 \cdot 10^{19}$ \\
\hline $\begin{array}{l}\text { Mobility } \\
\left(\mathrm{cm}^{2} \mathrm{~V}^{-1} \mathrm{~s}^{-1}\right)\end{array}$ & 3.5 & 8.0 \\
\hline Resistivity $(\Omega \cdot \mathrm{cm})$ & $3.2 \cdot 10^{-3}$ & $6.5 \cdot 10^{-2}$ \\
\hline
\end{tabular}

Table 2: Properties of the films grown by PLD on $\mathrm{SrTiO}_{3}(001)$.

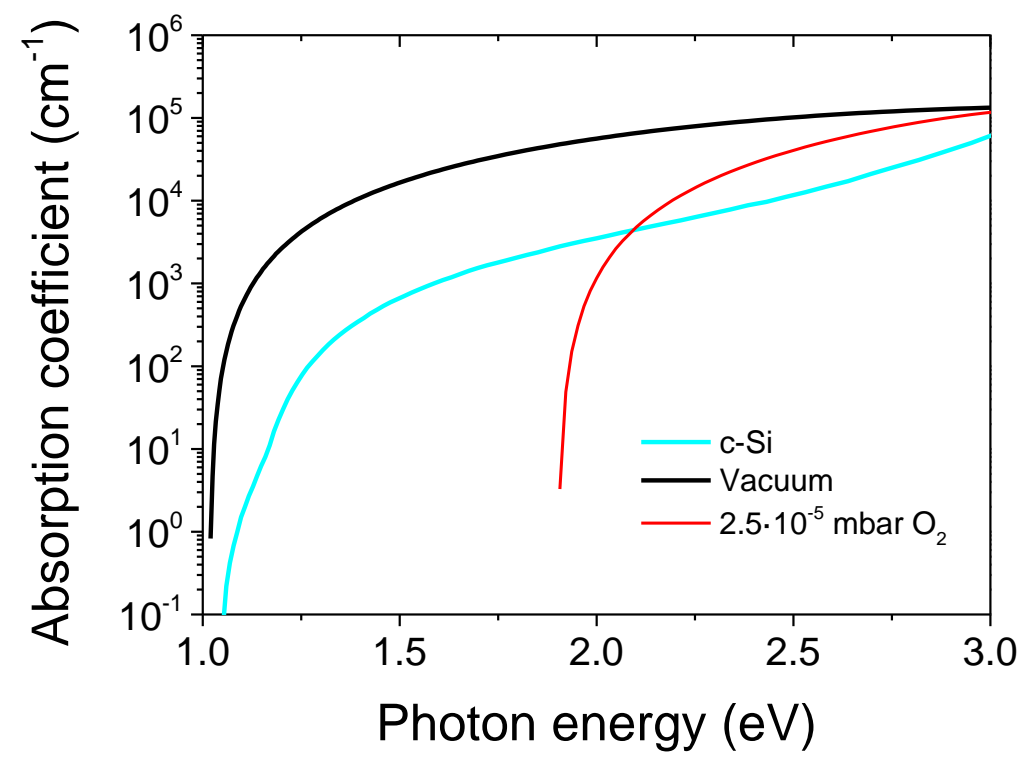

Figure 2: Absorption coefficient vs. photon energy for STO (001)//LVO samples grown by PLD. A c-Si spectrum is plotted for comparison. 


\section{Solution processed films}

The second method investigated to grow LVO is spin-coating of a sol-gel solution on quartz substrates. This technique could enable low cost deposition without the use of vacuum chambers. The experimental protocol is described in the experimental section. As shown in Figure 3, LVO was obtained without any parasitic phases visible in XRD and with a XRD pattern that follows very well the bulk LVO reference. The level of crystallization was found to be much higher than with the sputtering technique.

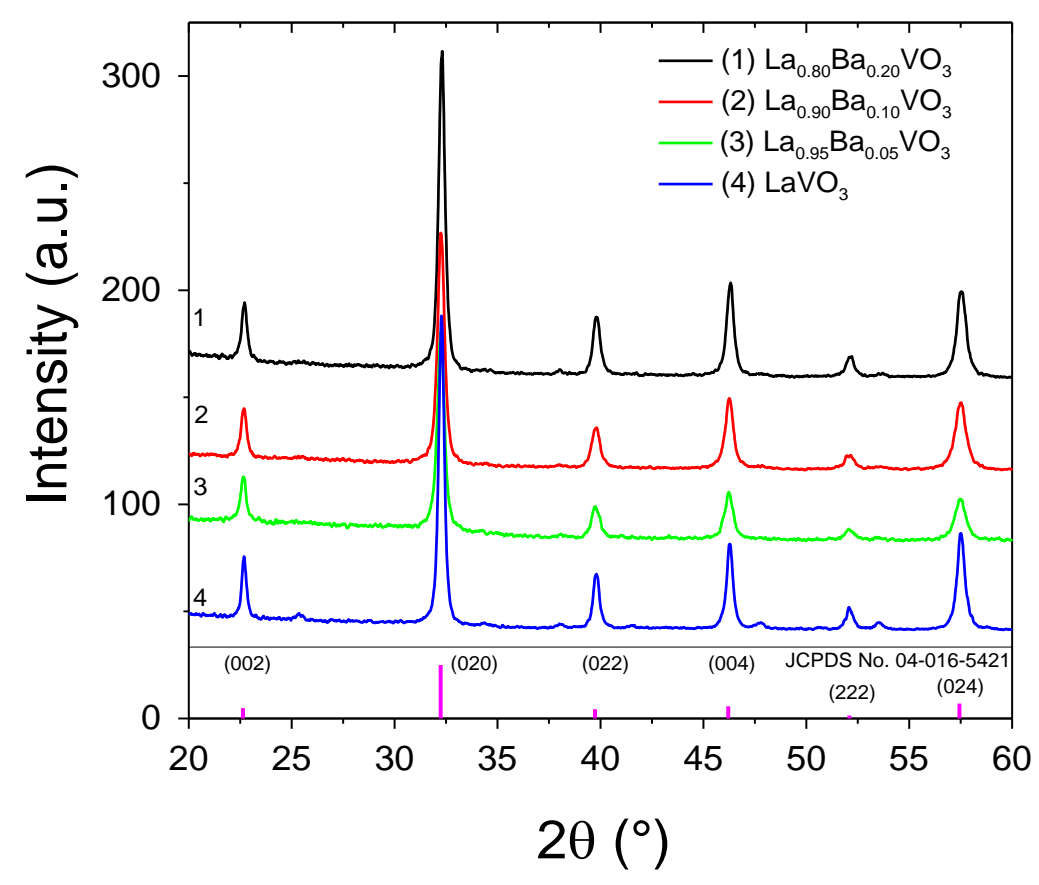

Figure 3: Room temperature XRD spectra showing solution processed LVO-based samples.

Table 3 describes the optical and electrical properties of the sol-gel LVO sample. The optical bandgap is $1.2 \mathrm{eV}$ and the carrier density is in the $10^{21} \mathrm{~cm}^{-3}$ range (n-type). Such a value is quite high to be used in a single gap solar cell absorber because of high Auger recombinations. Therefore, we fabricated LVO samples were La is partially substituted by Ba, in order to reduce the carrier density. Ba was chosen because it has similar characteristics to La being just one atomic number below La in the periodic table. The Ba concentration in La 1 ${ }_{x} B_{x} V O_{3}$ was varied from $x=0.05$ to $x=0.2$. The LVO crystallographic structure was preserved as shown in Figure 3. All these samples provided an optical bandgap of $1.4 \mathrm{eV}$ and the carrier concentration was not greatly reduced compared to the pure LVO samples. 
From Table 3, we can interpret the evolution of the electrical properties in the following way: for $x=0$, the film is $n$-type, for $x=0.05$ it is still $n$-type, and for $x=0.1$ and $x=0.2$ the materials behave as a compensated semiconductor where both n-type and p-type carriers are present.

\begin{tabular}{|l|c|c|c|c|}
\hline & LaVO $_{3}$ & La $_{0.95} \mathrm{Ba}_{0.05} \mathrm{VO}_{3}$ & ${\text { La } .9 \mathrm{Ba}_{0.1} \mathbf{V O}_{3}}$ & La $_{0.8} \mathrm{Ba}_{0.2} \mathbf{V O}_{3}$ \\
\hline Bandgap (eV) & 1.2 & 1.4 & 1.4 & 1.4 \\
\hline Carrier density & $\mathrm{n} 1.2 \cdot 10^{21}$ & $\mathrm{n} 2.7 \cdot 10^{21}$ & $\mathrm{n} 2.8 \cdot 10^{21}$ & $\mathrm{n} 9.0 \cdot 10^{20}$ \\
$\left(\mathrm{~cm}^{-3}\right)$ & & & $\mathrm{p} 3.0 \cdot 10^{20}$ & $\mathrm{p} 2.4 \cdot 10^{21}$ \\
\hline Mobility & 0.3 & 0.1 & $\mathrm{n} 0.8$ & $\mathrm{n} 0.3$ \\
$\left(\mathrm{~cm}^{2} \mathrm{~V}^{-1} \mathrm{~s}^{-1}\right)$ & & & $\mathrm{p} 0.5$ & $\mathrm{p} 0.1$ \\
\hline Resistivity & $2.5 \cdot 10^{-2}$ & $2.2 \cdot 10^{-2}$ & $3.9 \cdot 10^{-2}$ & $2.8 \cdot 10^{-2}$ \\
$(\Omega \cdot \mathrm{cm})$ & & & & \\
\hline
\end{tabular}

Table 3: Electrical properties of the films grown by spin-coating on quartz.

The substitution of La for Ba did not lead to a reduction of carrier density, therefore we opted for a variation of the La/V ratio, which was realised using magnetron sputtering.

\section{Physical vapor deposition films}

The initial goal of this experiment was to obtain LVO films in a single reactive co-sputtering step. The sputtering power for the $\mathrm{V}$ target was varied while preserving the same sputtering power for the La target. The visual aspect of the films on quartz after deposition was transparent, indicating that $\mathrm{LaVO}_{4}$ was obtained and not $\mathrm{LaVO}_{3}$. Post-deposition annealing in $\mathrm{H}_{2}$ led to dark-colored films, indicating that $\mathrm{LaVO}_{4}$ was transformed into $\mathrm{LaVO}_{3}$, as confirmed by XRD (Figure 4). 


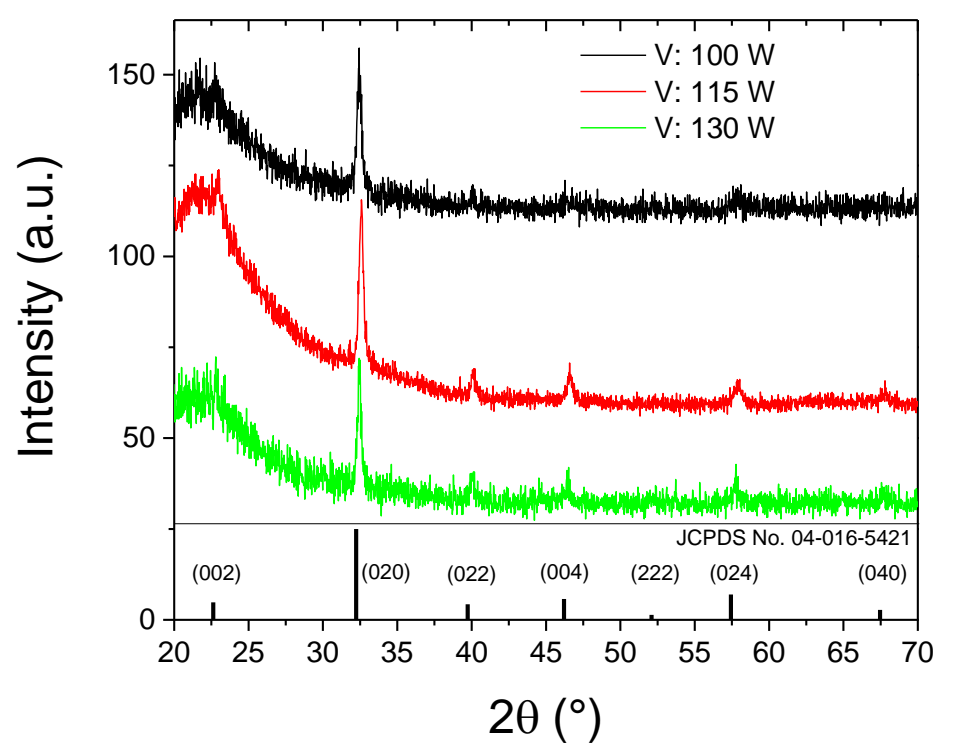

Figure 4: Room temperature $\theta-2 \theta$ XRD spectra showing quartz//LVO obtained by sputtering under $2 \mathrm{sccm} \mathrm{O}_{2}$ while varying $\mathrm{V}$ target power, after post-deposition annealing in $\mathrm{H}_{2}$. The corresponding database reference is plotted, showing that $\mathrm{LaVO}_{3}$ was obtained for all $\mathrm{V}$ power conditions.

Table 4 describes the different properties obtained for these samples in terms of deposition rate, composition, optical bandgap, carrier density, mobility and resistivity. The films provided low deposition rates, which is typical of oxides. The composition measured by RBS indicates that the La/ $\mathrm{V}$ ratio can be tuned with the $\mathrm{V}$ target power. The oxygen content is either under stoichiometric or over stoichiometric depending on the $\mathrm{V}$ target power compared to the ideal $\mathrm{ABO}_{3}$ perovskite structure.

Concerning the electrical properties, samples were showing both $\mathrm{p}$-type and n-type behavior when measured with the Van der Paw Hall effect technique. This can be attributed to the fact that the thin film is not homogeneous and the flow of electrons takes a different path for each measurement. The values indicated for the carrier concentration and mobility correspond to an average of several sets of measurements. At room temperature, the carrier concentration, mobility and resistivity can be varied in the $10^{15}-10^{20} \mathrm{~cm}^{-3}, 0.2-7.1 \mathrm{~cm}^{2} \mathrm{~V}^{-1} \mathrm{~s}^{-1}$, and 0.2 to $1.9 \cdot 10^{3} \Omega \cdot \mathrm{cm}$ range respectively. When the La/V concentration ratio is too high or 
too low compared to the ideal fully stoichiometric LVO, the carrier density is low compared to the bulk LVO value $\left(3 \cdot 10^{19} \mathrm{~cm}^{-3}\right.$, Madelung et al., 2000), and the mobility and resistivity are high. The fully stoichiometric LVO was found complicated to obtain using this technique because of the oxidation of the La target that was kept in a sealed atmosphere between each set of runs.

As for the optical properties, the optical bandgap was estimated using UV-visible spectrophotometry. The results correspond to an indirect transition crystal (Kittel, 1996) with a direct bandgap in the 3.7-4.1 eV range and an indirect bandgap in the 1.5-2 eV range (Table 4).

\begin{tabular}{|c|c|c|c|}
\hline \multirow[t]{2}{*}{ After $\mathrm{H}_{2}$ reduction } & \multicolumn{3}{|c|}{ Sputtering power for $\mathrm{V}(\mathrm{W})$} \\
\hline & 100 & 115 & 130 \\
\hline Deposition rate $(\mathrm{nm} / \mathrm{min})$ & 0.58 & 0.61 & 0.72 \\
\hline Composition & $\mathrm{La}_{1} \mathrm{~V}_{0.65} \mathrm{O}_{2.5}$ & $\mathrm{La}_{1} \mathrm{~V}_{1.3} \mathrm{O}_{3.7}$ & $\mathrm{La}_{1} \mathrm{~V}_{1.4} \mathrm{O}_{3.6}$ \\
\hline Optical bandgap (eV) & $\begin{array}{l}3.7 \mathrm{eV} \text { direct } \\
2.0 \mathrm{eV} \text { indirect }\end{array}$ & $\begin{array}{l}3.9 \mathrm{eV} \text { direct } \\
1.5 \mathrm{eV} \text { indirect }\end{array}$ & $\begin{array}{l}4.1 \mathrm{eV} \text { direct } \\
1.5 \text { indirect }\end{array}$ \\
\hline Carrier concentration $\left(\mathrm{cm}^{-3}\right)$ & $\begin{array}{l}\text { p } 2.4 \cdot 10^{15} \\
\text { n } 4.9 \cdot 10^{14}\end{array}$ & $\begin{array}{l}\text { p } 6.4 \cdot 10^{20} \\
\text { n } 9.0 \cdot 10^{19}\end{array}$ & $\begin{array}{l}\text { p } 1.6 \cdot 10^{18} \\
\text { n } 2.0 \cdot 10^{18}\end{array}$ \\
\hline Mobility $\left(\mathrm{cm}^{2} \mathrm{~V}^{-1} \mathrm{~s}^{-1}\right)$ & $\begin{array}{l}\mathrm{p} 2.3 \\
\mathrm{n} 7.1\end{array}$ & $\begin{array}{l}\mathrm{p} 0.2 \\
\mathrm{n} 0.3\end{array}$ & $\begin{array}{l}\mathrm{p} 3.2 \\
\mathrm{n} 1.2\end{array}$ \\
\hline Resistivity $(\Omega \cdot \mathrm{cm})$ & $1.9 \cdot 10^{3}$ & 0.2 & 2.4 \\
\hline
\end{tabular}

Table 4: room temperature key properties of the LVO based films grown by sputtering on quartz. The values represent an average from several measurements.

\section{Solar cells fabrication and analysis}

Prior to fabrication of solar cells on the grown LVO films, we performed simulations in order to investigate their potential given their properties. The AFORS-Het simulation software was used to determine the potential of $\mathrm{p}$-LVO / $\mathrm{n}$-ZnO solar cells. The first concern was to determine how thick the LVO absorber should be in order to obtain a photocurrent. Figure 5 
shows the evolution of the open-circuit voltage ( $\left.V_{\text {oc }}\right)$, short-current density (Isc) and conversion efficiency $(\eta)$ while varying the LVO thickness. The following parameters were introduced in the software: a carrier density of $10^{19} \mathrm{~cm}-3$, an electron affinity of $4.66 \mathrm{eV}$, a mobility of $2 \mathrm{~cm}^{2} \mathrm{~V}^{-1} \mathrm{~s}^{-1}$ and for $\mathrm{ZnO}$ a thickness of $3 \mu \mathrm{m}$, a carrier density of $10^{18} \mathrm{~cm}^{-3}$ and an electron affinity of $4.4 \mathrm{eV}$.

It can be seen that the $V_{O c}$ does not vary much with the LVO thickness while the corresponding $\mathrm{I}_{\mathrm{sc}}$ and $\eta$ increase. This is not surprising because as the LVO thickness increases, more photons can be absorbed, especially in the higher wavelength range. It can be seen that according to these simulations a conversion efficiency of about $5 \%$ should be reached for $300 \mathrm{~nm}$ of LVO.

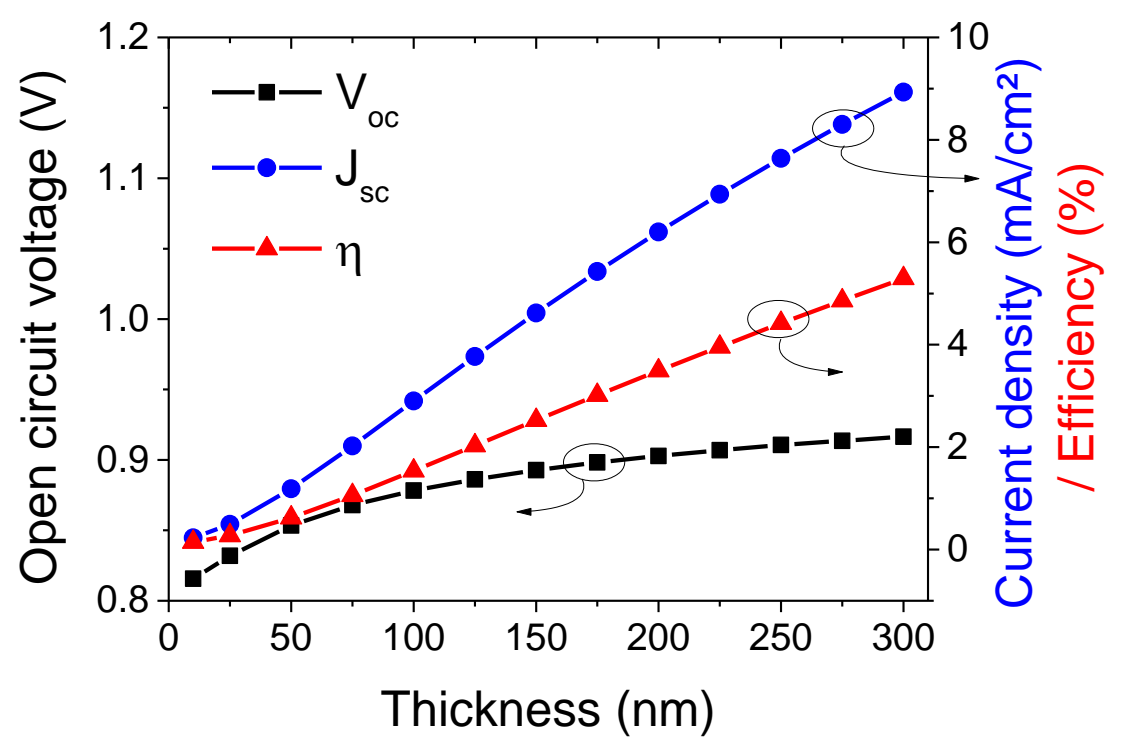

Figure 5: Evolution of the open circuit voltage, short-current density and efficiency simulated with a p-LVO / $\mathrm{n}$-ZnO junction using for LVO a carrier density of $10^{19} \mathrm{~cm}-3$, an electron affinity of $4.66 \mathrm{eV}$, a mobility of $2 \mathrm{~cm}^{2} \mathrm{~V}^{-1} \mathrm{~s}^{-1}$ and for $\mathrm{ZnO}$ a thickness of $3 \mu \mathrm{m}$, a carrier density of $10^{18} \mathrm{~cm}^{-3}$ and an electron affinity of $4.4 \mathrm{eV}$.

Solar cell structures were then fabricated. The first attempts were to grow LVO on c-Si (ntype) substrates, and LVO / ZnO on quartz substrates. Figure 6 shows the measured I-V 
characteristics obtained under AM1.5G illumination. The structure on silicon behaves as a very poor solar cell with a very low Isc. In this case, it is unknown if the photocurrent originates from photons absorbed in LVO or in Silicon. In the second case with the LVO/ZnO junction, no photocurrent is observed.
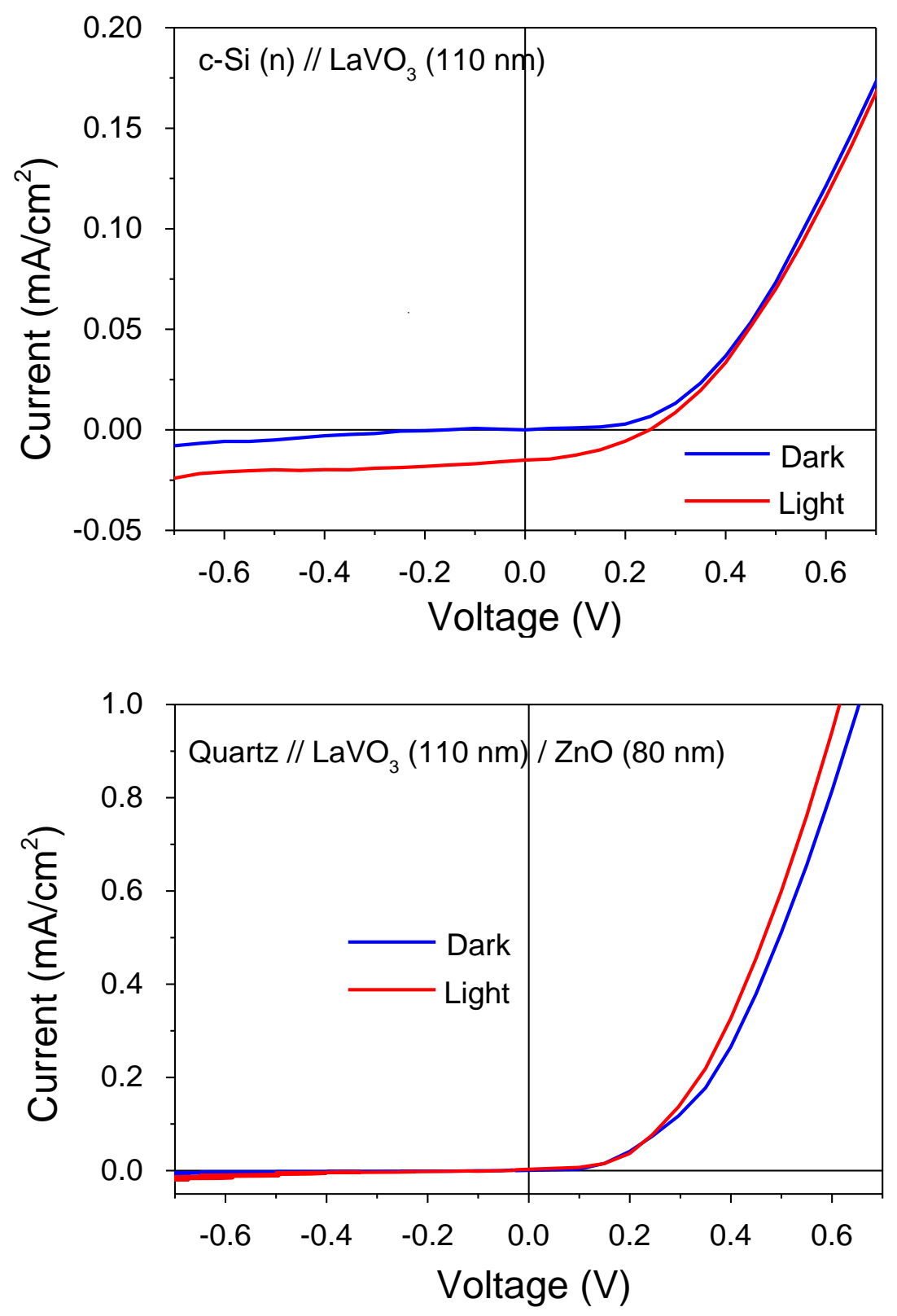

Figure 6: I-V characteristics of solar cell architectures under AM1.5G using LVO grown by physical vapor deposition (115 $\mathrm{W}$ for $\mathrm{V})$.

In order to understand why the solar cell structures are failing and further investigate the potential of the LVO films grown for PV, SPV and SKPM were carried on the samples with 
$100 \mathrm{~W}$ and $130 \mathrm{~W} \mathrm{~V}$ target power. To do so, a n-type ZnO layer was deposited at low temperature on the LVO films. No SPV signal originating from LVO could be detected. Figure 7 shows the topography of a sputtered LVO sample (130 W) grown on a quartz substrate. Ring-like structures of 5-10 $\mathrm{nm}$ depth can be observed, that are probably due to molecular impact during sputtering. The $130 \mathrm{~W}$ power for $\mathrm{V}$ is too high to prevent the formation of these rings. The RMS roughness is $5 \pm 1 \mathrm{~nm}$. When the thickness of the films increases, the rings tend to be shallower and less present. Grain boundaries can be observed which can be due to strain at the interface with the quartz substrates.
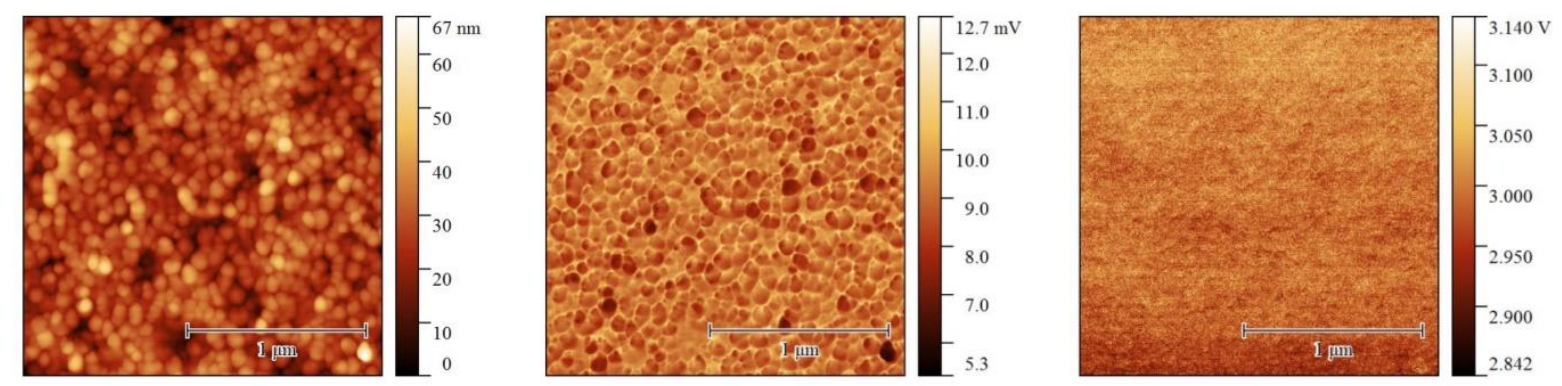

Figure 7: Room temperature AFM topography (left) EFM signal (middle) and SKPM map (right) for a sputtered LVO sample grown) grown on quartz substrate (130 W power on $\mathrm{V}$ target). The film thickness is around $50 \mathrm{~nm}$.

The same region was measured by EFM (Figure 7). It shows that the EFM signal is highly correlated to the morphology of the sample. In contrast, the SKPM map (Figure 7) shows little correlation between the morphology and the SKPM signal, within the sensitivity of the technique, which indicates that the settings used for SKPM are reliable. Thus, SKPM was used to determine the contact potential difference (CPD), that is the difference between the Au tip and the sample workfunctions. To extract the barrier height between $\mathrm{ZnO}$ and LVO, a layer of ZnO was sputtered on the LVO film through a mask, so that LVO was only partially covered by $\mathrm{ZnO}$ and both workfunctions could be extracted. A barrier height value at the $\mathrm{LaVO}_{3} / \mathrm{ZnO}$ interface equal to $0.125 \mathrm{~V}$ was observed. Current-voltage characteristic show a built-in potential around $0.1 \mathrm{~V}$, in very good agreement with the barrier height evaluated by SKPM. In addition, SKPM has also allowed to determine the surface potential, and thus individual work functions (WF) of $\mathrm{ZnO}$ and $\mathrm{LaVO}_{3}$. From these measurements, a WF of 
around $4.6 \mathrm{eV}$ and $4.5 \mathrm{eV}$ were obtained for sputtered LVO (130 W) and ZnO respectively. It is noteworthy that the measured value of the work function of $\mathrm{LaVO}_{3}$ has never been reported in literature up to now. Surface photovoltage spectroscopy on $\mathrm{LaVO}_{3}$ gave a signal below the detection limit of the apparatus. In fact, the evaluated barrier height value indicates that photogenerated electron-hole pairs are inefficiently separated and thus collected. This can explain the behaviour in the I-V characteristic, where dark and light current-voltage characteristics almost overlap. SPV signal could not be measured if the free carriers are not efficiently separated and collected.

In order to verify this hypothesis, simulations of the energy levels in the ZnO/LVO junction were performed, using this time electron affinity for LVO of $4.8 \mathrm{eV}$ and higher. Figure $8 \mathrm{a}$ clearly shows the barrier height in the conduction band between LVO and ZnO. This barrier prevents the establishment of a photocurrent.

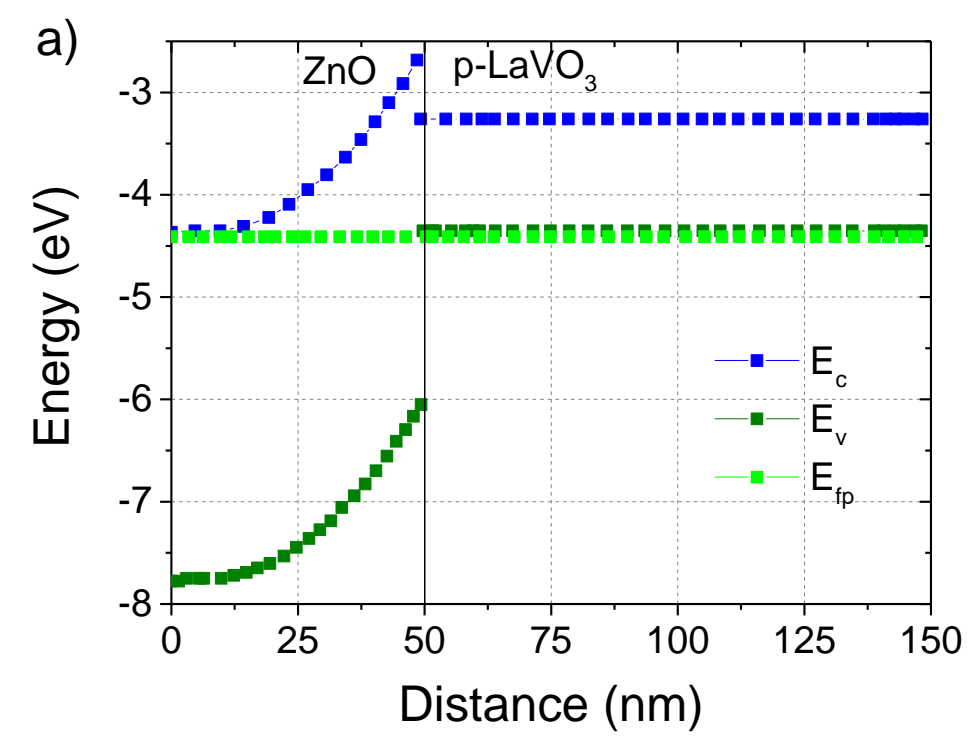




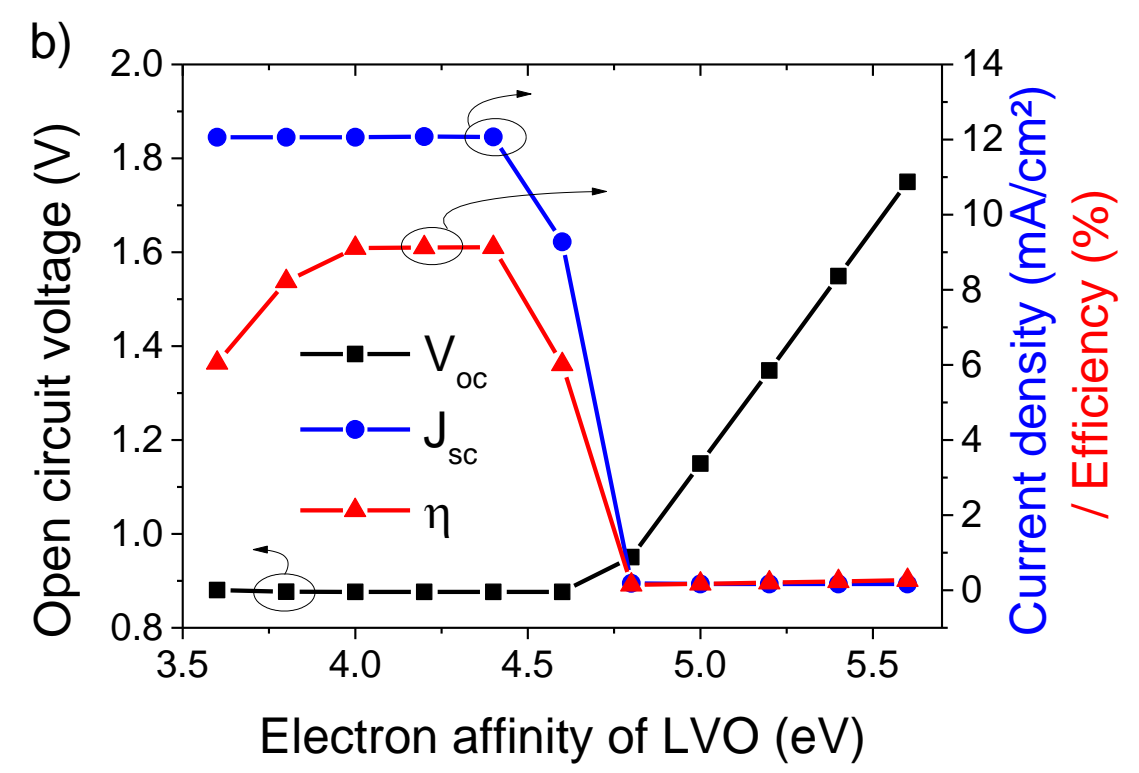

Figure 8: (a) Calculated band diagram for a $\mathrm{ZnO} / \mathrm{p}$-LVO based solar cell with a carrier density of $10^{18} \mathrm{~cm}^{-3}$ and an electron affinity $\geq 4.8 \mathrm{eV}$ for LVO. (b) Calculated evolution of the opencircuit voltage, short-circuit current, and conversion efficiency of a $\mathrm{ZnO} / \mathrm{p}$-LVO based solar cell vs. LVO electron affinity with a carrier density of $10^{18} \mathrm{~cm}^{-3}$ for LVO.

Figure $8 \mathrm{~b}$ shows the evolution of the open-circuit voltage, current density and conversion efficiency while varying the electron affinity of LVO. It shows as well that when the electron affinity of LVO is too high ( $\geq 4.6 \mathrm{eV}$ ) the current density and efficiency drop to almost zero. Because the experimental WF of LVO is so high (4.6 eV), the way to achieve a working LVO all-oxide solar cell would be to find an oxide with a much higher WF. In practice, such oxides are scarce. Molybdenum oxides $\left(\mathrm{MoO}_{\mathrm{x}}\right)$ that are sometimes used in organic solar cells could play this role (Talik et al., 2016), however our attempts to obtain $\mathrm{MoO}_{\mathrm{x}} / \mathrm{LVO}$ solar cells failed, probably because this material is not very stable and is generally used as a very thin layer.

Another concern is the influence of the carrier density of LVO. A too high carrier density of the absorber in a solar cell will lead to Auger recombination, which will be detrimental for the performance of the solar cell. Figure 9 shows the evolution of the open-circuit voltage, short-current density and conversion efficiency while varying the LVO carrier density. It can be seen that when the carrier density is increased from $10^{16}$ to $10^{21} \mathrm{~cm}^{-3}$, the short-circuit current and conversion efficiency drop to very low values already at $10^{18} \mathrm{~cm}^{-3}$. To take this 
effect into account experimentally, we fabricated LVO/ZnO structures with $50 \mathrm{~W}$ sputtering power for $V$ so that the LVO carrier density would be in the $10^{15} \mathrm{~cm}^{-3}$ range. No short-circuit current was obtained, probably due to a wrong band alignment as mentioned earlier.

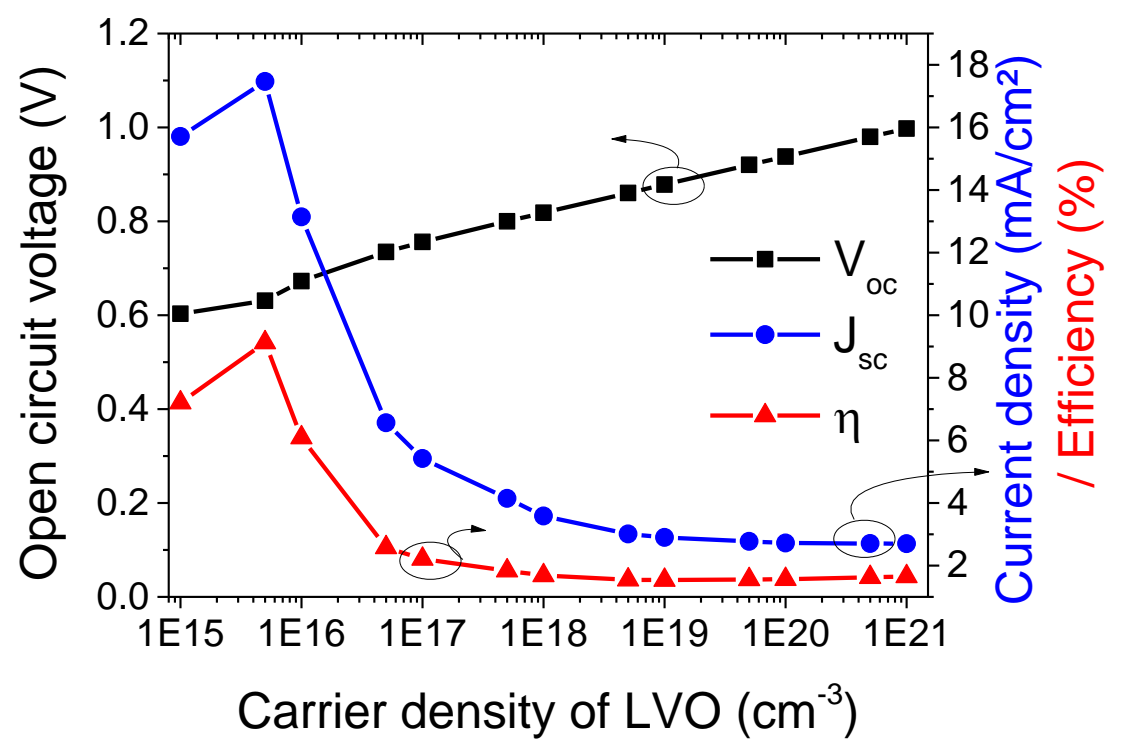

Figure 9: Evolution of the open circuit voltage, short-current density and efficiency simulated with a $\mathrm{p}$-LVO / $\mathrm{n}$-ZnO junction while varying the carrier density of LVO, using for LVO an electron affinity of $4.66 \mathrm{eV}$, a mobility of $2 \mathrm{~cm}^{2} \mathrm{~V}^{-1} \mathrm{~s}^{-1}$ and for $\mathrm{ZnO}$ a thickness of $3 \mu \mathrm{m}$, a carrier density of $10^{18} \mathrm{~cm}^{-3}$ and an electron affinity of $4.4 \mathrm{eV}$.

To overcome the limitation of the poor carrier transport properties of these grown LVO films, a solution could be the incorporation of an additional electron-transport material and hole-transport material into a structure similar to the design of dye-sensitized solar cells, as proposed by Wang et al., 2015. In such a structure, a huge number of internal interfaces between the individual solar absorber and nanostructured charge transport media would enable the separation and collection of photogenerated electron-hole pairs. 


\section{Conclusion}

In this work, we have demonstrated the possibility to grow LVO films using the PLD technique in addition to two more methods, namely spin coating from a sol-gel solution and magnetron sputtering. The advantages of the last novel methods are the upscaling to large surfaces in addition to a possible tuning of the conduction properties of LVO. Another interesting feature is that LVO has been demonstrated to be a semiconductor with a high work function ( $4.6 \mathrm{eV}$ ) which is not often observed.

In terms of applications to photovoltaics, thanks to extensive analyses, including SPV measurements which are sensitive to transport properties besides the optical ones, we have clearly shown that LVO material is a poor charge-transport medium and therefore, is not suitable as base material for solar cells. It is suggested to improve the charge transport properties by adding materials (electron and/or hole rich) or structuring the cell (interfaces) to allow a more efficient charges separation. Recent experiments on LVO grown by hybrid molecular beam epitaxy have shown that stoichiometry is key for obtaining large photoconductivity (Zhang et al., 2017). Furthermore, following the recent developments of $\mathrm{NiO}$ solar cells by Nakai et al., 2017, that enables transparent to visible light solar cells for window applications, LVO seems an interesting material to be incorporated in these structures because of the band alignment with $\mathrm{NiO}$ and large work function of LVO. As well, compounds related to LVO are being investigated for solar cells, such as $\mathrm{LaRhO}_{3}$ (Nakamura et al., 2015).

These considerations could pave the way for future developments on the study and optimization of LVO perovskite as a material for photovoltaic applications.

\section{Acknowledgments}

The authors thank G. Versini for assistance with PLD deposition. This research was partially funded by the Centre National de la Recherche Scientifique exploratory project grant "PEROPV" and carried out under the framework of the FERROPV project supported by the French Agence Nationale de la Recherche (ANR) under the reference ANR-16-CE05-0002-01. 
We acknowledge Prof. Tom Wu from KAUST University and Prof. Aaron Walsh from Imperial College London for valuable insight. Margherita Sola, now at the Tetra Pak Rubiera (RE) Italy, is gratefully acknowledged for SPV measurements. 


\section{References}

Arima et al., 1993 T. Arima, Y. Tokura, J. B. Torrance

Variation of optical gaps in perovskite-type 3D transition-metal oxides

Phys. Rev. B 48 (1993), p. 17006.

Assmann et al., 2013 E. Assmann, P. Blaha, R. Laskowski, K. Held, S. Okamoto, and G. Sangiovanni

\section{Oxide Heterostructures for Efficient Solar Cells}

Phys. Rev. Lett. 110 (2013), p. 078701.

Bordet et al., 1993 P. Bordet, C. Chaillout, M. Marezio, Q. Huang, A. Santoro, S. W. Cheong, H. Takagi, C. S. Oglesby, and B. Batlogg

Structural aspects of the crystallographic magnetic transition in $\mathrm{LaVO}_{3}$ around $140 \mathrm{~K}$ J. Solid State Chem. 106 (1993), p. 253.

Cavalcoli et al., 2015 D. Cavalcoli, B. Fraboni, A. Cavallini

Chapter Seven-Surface and Defect States in Semiconductors Investigated by Surface Photovoltage

Semiconductors and Semimetals, Elsevier 2015.

Chakrabartty et al., 2013 J. P. Chakrabartty, R. Nechache, C. Harnagea, and F. Rosei Photovoltaic effect in multiphase Bi-Mn-O thin films.

Opt. Express 22 (2013), p. A80.

Charlebois et al., 2013 M. Charlebois, S. R. Hassan, R. Karan, D. Sénéchal, and A.-M. S. Tremblay, Mott $p-n$ junctions in layered materials Phys. Rev. B 87 (2013), p. 035137. 
Chen et al., 2012 B. Chen, Z. Zuo, Y. Liu, Q.-F. Zhan, Y. Xie, H. Yang, G. Dai, Z. Li, G. Xu and R.W. Li

Tunable photovoltaic effects in transparent $\mathrm{Pb}\left(\mathrm{Zr}_{0.53}, \mathrm{Ti}_{0.47}\right) \mathrm{O}_{3}$ capacitors Appl. Phys. Lett. 100 (2012), p. 173903.

Choi et al., 2010 W. Choi, S. Y. Lee, and T. D. Sands

Capacitance-voltage characteristics of $\mathrm{SrTiO}_{3} / \mathrm{LaVO}_{3}$ epitaxial heterostructures Appl. Phys. Lett. 96 (2010), p. 212903.

Dimopoulos et al., 2013 T. Dimopoulos, A. Peic, P. Mullner, M. Neuschitzer, R. Resel, S. Abermann, M. Postl, E. J. W. List, S. Yakunin, W. Heiss, H. Bruckl Photovoltaic properties of thin film heterojunctions with cupric oxide absorber J. Renew. Sustain. Ener. 5 (2013), p. 011205.

Fix et al., 2009 T. Fix, F. Schoofs, J.L. MacManus-Driscoll, and M.G. Blamire Charge Confinement and Doping at $\mathrm{LaAlO}_{3} / \mathrm{SrTiO}_{3}$ Interfaces Phys. Rev. Lett. 103 (2009), p. 166802.

Gharetape et al., 2011 S. Jamali Gharetape, M. P. Singh, F. S. Razavi, D. A. Crandles, L. Y. Zhao, and K. T. Leung

Effect of vanadium deficiency on properties of polycrystalline $\mathrm{LaVO}_{3}$. Appl. Phys. Lett. 98 (2011), p. 052509.

Han et al., 2015 H. Han, S. Song, J. H. Lee, K. J. Kim, G.-W. Kim, T. Park, and H. M. Jang Switchable Photovoltaic Effects in Hexagonal Manganite Thin Films Having Narrow Band Gaps.

Chem. Mater. 27 (2015), p. 7425.

He et al., 2012 He, C.; Sanders, T. D.; Gray, M. T.; Wong, F. J.; Mehta, V. V.; Suzuki, Y.

Metal-insulator transitions in epitaxial $\mathrm{LaVO}_{3}$ and $\mathrm{LaTiO}_{3}$ films

Phys. Rev. B 86 (2012), p. 081401(R).

Hotta et al., 2006 Y. Hotta, Y. Mukunoki, T. Susaki, H. Y. Hwang, L. Fitting, and D. A. Muller Growth and epitaxial structure of LaVO $_{x}$ films Appl. Phy. Lett. 89 (2006), p. 031918. 
Hotta et al., 2007 Y. Hotta, T. Susaki, and H. Y. Hwang

Polar discontinuity doping of the $\mathrm{LaVO}_{3} / \mathrm{SrTiO}_{3}$ interface

Phys. Rev. Lett. 99 (2007), p. 236805.

levskaya et al., 2015 Y. levskaya, R.L.Z. Hoye, A. Sadhanala, K.P. Musselman, J.L. MacManusDriscoll

Fabrication of $\mathrm{ZnO} / \mathrm{Cu}_{2} \mathrm{O}$ heterojunctions in atmospheric conditions: Improved interface quality and solar cell performance

Sol. Energ. Mat. Sol. Cells 135 (2015), p. 43

Jellison et al., 1996 G. E. Jellison Jr and F. A. Modine

Parameterization of the optical functions of amorphous materials in the interband region Appl. Phys. Lett. 69 (1996), 371.

Kittel et al., 1996 C. Kittel

Introduction to Solid State Physics, 7th Ed., Wiley 1996.

Kupfer et al., 1996 B. Kupfer, K. Majhi, D. A. Keller, Y. Bouhadana, S. Rühle, H. N. Barad, A. Y. Anderson, and A. Zaban

Thin Film $\mathrm{CO}_{3} \mathrm{O}_{4} / \mathrm{TiO}_{2}$ Heterojunction Solar Cells

Adv. Energy Mater. 5 (2015), p. 1401007.

Madelung et al., 2000 O. Madelung, U. Rössler, M. Schulz,

$\mathrm{LaVO}_{3}$ crystal structure, physical properties

Landolt-Börnstein - Group III Condensed Matter 41E (Ternary Compounds, Organic

Semiconductors), Springer-Verlag Berlin Heidelberg 2000.

Manousakis, 2010 E. Manousakis

Photovoltaic effect for narrow-gap Mott insulators

Phys. Rev. B 82 (2010), p. 125109.

Masuno et al., 2004 A. Masuno, T. Terashima, M. Takano

Epitaxial growth of perovskite-type $\mathrm{LaVO}_{3}$ thin films on various substrates by the PLD method

Solid State Ion. 172 (2004), p. 275.

Minami et al., 2016 T. Minami, Y. Nishi, and T. Miyata

Efficiency enhancement using a $\mathrm{Zn}_{1-\mathrm{x}} \mathrm{Ge}_{\mathrm{x}}-\mathrm{O}$ thin film as an n-type window layer in $\mathrm{Cu}_{2} \mathrm{O}$ - 
based heterojunction solar cells

Appl. Phys. Express 9 (2016), p. 052301.

Nakai et al., 2017 H. Nakai, M. Sugiyama, and S. F. Chichibu

Ultraviolet light-absorbing and emitting diodes consisting of a p-type transparentsemiconducting NiO film deposited on an n-type GaN homoepitaxial layer Appl.Phys. Lett. 110 (2017), p. 181102.

Nakamura et al., 2010 M. Nakamura, A. Sawa, J. Fujioka, M. Kawasaki, and Y. Tokura Interface band profiles of Mott-insulator/ $\mathrm{Nb}: \mathrm{SrTiO}_{3}$ heterojunctions as investigated by optical spectroscopy.

Phys. Rev. B 2010, 82, 201101(R).

Nakamura et al., 2007 M. Nakamura, A. Sawa, H. Sato, and H. Akoh, M. Kawasaki, Y. Tokura Optical probe of electrostatic-doping in an $n$-type Mott insulator Phys. Rev. B 75 (2007), p. 155103.

Nakamura et al., 2015 M. Nakamura, Y. Krockenberger, J. Fujioka, M. Kawasaki, and Y. Tokura

Perovskite $\mathrm{LaRhO}_{3}$ as a $p$-type active layer in oxide photovoltaics Appl. Phys. Lett. 106 (2015) p. 072103.

Nechache et al., 2015 R. Nechache, C. Harnagea, S. Li, L. Cardenas, W. Huang, J. Chakrabartty and F. Rosei

Bandgap tuning of multiferroic oxide solar cells

Nature Phot. 9 (2015), p. 61.

ParkAFM, 2017 http://www.parkafm.com/index.php/parl-spm-

modes/dielectricpiezoelectric- properties/228-electric-force-microscopy-efm.

Tiwari et al., 2015 D. Tiwari, D. J. Fermin, T. K. Chaudhuri, and A. Ray

Solution Processed Bismuth Ferrite Thin Films for All-Oxide Solar Photovoltaics

J. Phys. Chem. C 119 (2015), p. 5872. 
Qin et al., 2008 M. Qin, K. Yao and Y. C. Liang

High efficient photovoltaics in nanoscaled ferroelectric thin films

Appl. Phys. Lett. 93 (2008), 122904.

Rotella et al., 2015 H. Rotella, O. Copie, A. Pautrat, P. Boullay, A. David, D. Pelloquin, C. Labbé, C. Frilay and W. Prellier,

Two components for one resistivity in $\mathrm{LaVO}_{3} / \mathrm{SrTiO}_{3}$ heterostructure

J. Phys.: Condens. Matter 27 (2015), p. 095603.

Soumahoro et al., 2011 I. Soumahoro, G. Schmerber, A. Douayar, S. Colis, M. Abd-Lefdil, N. Hassanain, A. Berrada, D. Muller, A. Slaoui, H. Rinnert, A. Dinia

Structural, optical, and electrical properties of $\mathrm{Yb}$-doped $\mathrm{ZnO}$ thin films prepared by spray pyrolysis method

J. Appl. Phys. 109 (2011), p. 033708.

Talik et al., 2016 N. A. Talik, K. L. Woon, B. K. Yap, W. S. Wong, T. J. Whitcher, N. Chanlek, H. Nakajima, T. Saisopa, and P. Songsiririthigul

Highly efficient processable molybdenum trioxide as a hole blocking interlayer for superyellow organic light emitting diode

J. Phys D: Appl. Phys. 49 (2016), p. 395105.

Wang et al., 2015 L. Wang, Y. Li, A. Bera, C. Ma, F. Jin, K. Yuan, W. Yin, A. David, W. Chen, W. Wu, W. Prellier, S. Wei, and T. Wu,

Device Performance of the Mott Insulator $\mathrm{LaVO}_{3}$ as a Photovoltaic Material Phys. Rev. Applied 3 (2015), p. 064015.

Warasawa et al., 2013 M. Warasawa, Y. Watanabe, J. Ishida, Y. Murata, S. F. Chichibu, and M. Sugiyama

Fabrication of Visible-Light-Transparent Solar Cells Using p-Type NiO Films by Low Oxygen Fraction Reactive RF Sputtering Deposition

Jap. J. Appl. Phys. 52 (2013), p. 021102.

Webb et al., 1976 J. H. Webb, M. Sayer

High-temperature transport in lanthanum strontium vanadate

J. Phys. C 9 (1976), p. 4151. 
Zhang et al., 2017 H.-T. Zhang, M. Brahlek, X. Ji, S. Lei, J. Lapano, J. W. Freeland, V. Gopalan, and R. Engel-Herbert

High-Quality $\mathrm{LaVO}_{3}$ Films as Solar Energy Conversion Material

ACS Appl. Mater. Interfaces, 9 (2017), p. 12556. 